\title{
PANORAMA DA PRODUÇ̃̃o CIENTÍFICA E ACADÊMICA À PARTIR DO PROJETO OBSERVATÓRIO DA EDUCAÇÃO COM FOCO EM MATEMÁTICA E INICIAÇÃO EM CIÊNCIAS - UFMT
}

\author{
SCIENTIFIC AND ACADEMIC PRODUCTION OVERVIEW FROM EDUCATION \\ OBSERVATORY PROJETCT FOCUSING ON MATHEMATICS AND SCIENCE \\ INITIATION - UFMT
}

RESUMEN DE PRODUCCIÓN CIENTÍFICA Y ACADÉMICA A PARTIR DEL PROYECTO OBSERVATORIO DE EDUCACIÓN ENFOCADO EN INICIACIÓN EN MATEMÁTICAS Y CIENCIAS - UFMT

Jacqueline Borges de Paula*(D) $(9$

\begin{abstract}
RESUMO
Nosso objetivo é traçar um panorama descritivo da Produção Científica e Acadêmica (2011-2019) resultante de processos formativos e de pesquisas desenvolvidas no Projeto Observatório da Educação com Foco em Matemática e Iniciação em Ciências - OBEDUC - Polo UFMT. Apresentamos o mapeamento e a descrição das tendências temáticas e metodológicas, áreas e subáreas envolvidas e fontes para coleta de dados. Metodologicamente, realizamos investigação qualitativa de abordagem interpretativa, aportada em pesquisas de tipologia "estado da arte". Este inventário contribui com a construção de processos formativos situados, ao mesmo tempo em que podemos rever tendências, analisar resultados e refletir sobre possibilidades e limitações de programas como o OBEDUC.
\end{abstract}

Palavras-chave: OBEDUC. Formação de Professores. Produção Científica e Acadêmica.

\section{ABSTRACT}

Our objective is to draw a descriptive panorama of Scientific and Academic Production (2011-2019) resulting from training processes and research carried out in the Education Observatory Project focusing on Mathematics and Initiation in Science - OBEDUC - UFMT Pole. We present a mapping-out and the description of both thematic and methodological trends, related areas and sub-areas as well as sources for data collection. Methodologically, we carry out qualitative investigation with interpretative approach, supported by "state-of-the-art" typology research. This inventory can contribute to the construction of situated training processes, while we can review trends, analyze results, and reflect on the possibilities and limitations of programs such as OBEDUC.

Keywords: OBEDUC. Teacher Training. Scientific and Academic Production.

\section{RESUMEN}

Nuestro objetivo es trazar un panorama descriptivo de la Producción Científica y Académica (20112019) resultante de los procesos de formación e investigación realizados en el Proyecto Observatorio Educativo con Enfoque Matemática e Iniciación a las Ciencias - OBEDUC - Polo UFMT. Presentamos

\footnotetext{
* Doutora em Educação Matemática pela Universidade Federal de Mato Grosso (UFMT). Professora Adjunta do Departamento de Ensino e Organização Escolar, na Graduação de Pedagogia, do Instituto de Educação da Universidade Federal de Mato Grosso (UFMT), na Cidade de Cuiabá, Estado de Mato Grosso Brasil. Endereço para correspondência: Rua Fortaleza, 364, centro, Município de Campo Verde, estado de Mato Grosso, CEP 78840-000. E-mail jbcaula@yahoo.com.br.
} 
el mapeo y descripción de tendencias temáticas y metodológicas, áreas y subáreas involucradas y fuentes para la recolección de datos. Metodológicamente, realizamos una investigación cualitativa con enfoque interpretativo, sustentada en investigaciones de tipología de "estado del arte". Este inventario contribuye a la construcción de procesos de formación situados, al mismo tiempo que podemos revisar tendencias, analizar resultados y reflexionar sobre las posibilidades y limitaciones de programas como OBEDUC.

Palabras clave: OBEDUC. Formación de professores. Producción científica y académica.

\section{INTRODUÇÃO}

Um aumento significativo e progressivo tem ocorrido, nas pesquisas em Educação Matemática e em Ciências o que podemos destacar em estudos como o de Megid Neto (1999), Teixeira e Megid Neto (2006), Fernandes e Megid Neto (2007), Teixeira (2008), Dias e Valadares (2010), e, Slongo e Megid Neto (2011). Sobretudo, esses estudos destacam produções direcionada à formação inicial e continuada de modo geral não detalhando sobre contribuições especificas de programas financiados pela CAPES.

Entendemos que, na última década, tais programas comparecem contribuindo significativamente neste aumento, de modo que, nos dedicamos aqui em destacar as produções decorrentes de ações desenvolvidas a partir do Programa OBEDUC no Projeto Observatório da Educação em Matemática e Iniciação à Ciências - Polo UFMT, com ações direcionadas à formação inicial e continuada de professores, objetivando a melhoria do processo ensinoaprendizagem.

Realizamos pesquisa de cunho qualitativo e abordagem bibliográfica ao inventariar a produção científica e acadêmica deste projeto neste polo objetivamos dar visibilidade, ao tempo em que, empreendendo um movimento à uma dimensão crítico-reflexiva ao panorama delineado. O Projeto OBEDUC - polo UFMT foi desenvolvido e operacionalizado de 2011 a 2015. Sobretudo, realizamos um mapeamento compreendendo o período de 2011 a 2019, buscando comtemplar toda a produção científica e acadêmica gerada e decorrente de ações neste projeto, uma vez que, trabalhos e estudos posteriores foram realizados posteriormente com base nos dados e registros produzidos. Procuramos construir uma reflexão que busca evidenciar tendências temáticas e metodológicas, espaços educativos envolvidos, e, categorias de sujeitos investigados, nos trabalhos e estudos realizados.

Efetuamos busca no repertório da CAPES à estudos e pesquisas que apresentassem um Panorama e/ou Estado da Arte de produções acadêmicas desenvolvidas a partir do Programa/Projeto OBEDUC, e, identificamos somente uma dissertação: “Um Panorama das 
Pesquisas em Formação Continuada de Professores de Matemática no Programa OBEDUC (2010 - 2015): uma caracterização da reflexibilidade docente", autoria de Jesus Reinaldo Alves Quirino, publicada em 2017. Quirino desenvolveu um estudo que teve como objetivo analisar pesquisas em Formação Continuada de Professores de Matemática, produzidas no Brasil, nos Programas de Pós-Graduação, vinculadas ao Programa OBEDUC, no período de 2010 a 2015, buscando caracterizar a Reflexividade Docente. O pesquisador mapeou 124 pesquisas desenvolvidas no Brasil, entre teses e dissertações defendidas no referido período, aprofundando sua análise sobre 5 dissertações nas quais encontrou indícios de reflexão do professor.

Inventariar a produção bibliográfica nesses programas e respectivos projetos pode contribuir para a projeção e direcionamento ao enfrentamento das situações-problema no processo ensino-aprendizagem, colaborando na construção de processos formativos situados (Formação inicial e Continuada) para professores que atuam, neste caso, com a Matemática e Ciências da Natureza nos Anos Iniciais do Ensino Fundamental, ao mesmo tempo em que podemos rever tendências, analisar resultados e refletir sobre possibilidades e limitações de programas como o OBEDUC.

De modo que consideramos salutar a reflexão aqui iniciada, pois, com maior amplitude e visibilidade das pesquisas realizadas e sobre a produção de conhecimento, temos mais subsídios ao direcionamento às políticas educacionais e aos programas direcionados à formação inicial e continuada dos professores.

\section{O PROJETO OBEDUC - POLO UFMT}

O Projeto Observatório da Educação com Foco em Matemática e Iniciação às Ciências (OBEDUC), aprovado pelo edital da CAPES no 038/2010, fez parte do Programa (de mesmo nome) financiado pela CAPES/INEP/SECADI e desenvolvido em rede, constituindo uma parceria entre três instituições de Ensino Superior: Universidade Estadual Paulista (UNESP, câmpus Ilha Solteira - SP), Universidade Estadual de Mato Grosso - (UNEMAT, câmpus Cáceres - MT) e Universidade Federal de Mato Grosso (UFMT, câmpus Cuiabá - MT).

Teve como objetivo fomentar estudos e pesquisas em educação, utilizando a infraestrutura disponível dessas instituições de Educação Superior - IES e as bases de dados existentes no INEP. Inseriram-se no programa, o qual visava, principalmente, proporcionar a articulação entre pós-graduação, licenciaturas e escolas da Educação Básica, estimulando a 
produção acadêmica e a formação e graduandos e pós-graduados, em nível de mestrado e doutorado.

Durante o período de suas atividades (2011 a 2015), o Projeto visou identificar dificuldades em Matemática e Ciências de estudantes (e de professores) das escolas públicas atendidas, realizar discussões sistemáticas em diferentes fóruns (locais e gerais) e coordenar as propostas de intervenção para enfrentar as problemáticas identificadas, sobretudo, in loco.

Cada uma das três universidades atendia a seis escolas de educação básica cuja equipe era constituída por um professor doutor (coordenador), um doutorando, três mestrandos, três licenciandos em Pedagogia e três em Matemática, seis professores coordenadores (um por escola), professores da educação básica e alunos das escolas contempladas.

Essa equipe orientava as ações desenvolvidas especificamente no Projeto - polo UFMT - por meio dos diagnósticos anuais das dificuldades dos alunos. Simulados eram elaborados nos moldes da Prova Brasil do MEC e aplicados em turmas que estariam sendo foco da atuação do Projeto. Para validação do diagnóstico gerado pelos simulados, os professores das respectivas turmas eram solicitados a responderem a questionários nos quais indicavam as dificuldades mais recorrentes em Matemática dos seus alunos. Os dados eram organizados, tabulados e os resultados encontrados possibilitavam direcionamentos às ações de formação dos professores, das ações de intervenção com os alunos nas unidades escolares e o estabelecimento e desenvolvimento de pesquisas.

Desta forma, procurava-se constituir um plano de ações a partir das necessidades apontadas pelos professores e diagnosticadas na dimensão dos alunos. Das unidades escolares à Universidade, destaca-se uma relação de permanente exercício de reflexão nos momentos de encontros de estudos para o planejamento das ações, fomentando sempre o diálogo, valorizando os saberes individuais e do grupo, ouvindo os pares e buscando direcionamentos em conjunto, para caminharmos na busca de soluções às problemáticas encontradas.

As ações desdobravam-se em três momentos: 1) momento de estudo, reflexão e planejamento sobre/das ações, envolvendo os membros diretamente (e bolsistas) comprometidos nos projetos; 2) oferta de encontros de formação continuada aos professores, nos quais, ou como minicursos ou como oficinas, eram produzidos materiais e realizavam-se discussões sobre metodologias e fundamentos teóricos para o processo ensino-aprendizagem; 3) intervenções com os alunos em sala de aula ou em horários de contraturno, visando ao enfrentamento de "dificuldades de aprendizagens" e, numa dimensão mais global, articulando a possibilidade de reflexos relacionados aos índices do IDEB, que é calculado levando em 
consideração as médias de desempenho na prova de proficiência em Matemática. Perpassavam, transversalmente, esses três momentos, as pesquisas que eram estruturadas e realizadas, especificamente pelos mestrandos e doutorandos, membros no Projeto.

Tais pesquisas subsidiavam direcionamentos às ações de formação que eram operacionalizadas no Projeto. A intervenção junto aos professores das escolas e a formação continuada eram conduzidas pelos mestrandos do PPGE - IE da UFMT, também bolsistas. Com os alunos, nas unidades escolares, o trabalho era desenvolvido pelos bolsistas graduandos da UFMT dos cursos de Pedagogia (intervenção nos Anos Iniciais) e de Matemática (intervenção nos Anos Finais). É interessante salientar que tanto as atividades de intervenção junto aos alunos quanto a formação continuada dos professores eram anteriormente organizadas em encontros semanais pelos integrantes do Projeto.

O programa esteve fundamentado numa ambiência educativa de articulação entre escola e universidade, teoria e prática, ensino e pesquisa. E, ao fomentar a dimensão da pesquisa imbricada ao processo de ensino, defendia, como diz Paulo Freire (2001), que não é no silêncio que os homens se fazem, mas na palavra, no trabalho, na ação-reflexão.

\section{PROCEDIMENTO METODOLÓGICO}

Entendemos neste estudo que o nosso percurso metodológico é de cunho qualitativo e abordagem interpretativa dos dados; sobretudo, desenhamos, ao levantamento da produção bibliográfica do Projeto OBEDUC - Polo UFMT, um caminho que coaduna com o de pesquisas relacionadas com o 'estado da arte', principalmente destacado no caráter bibliográfico das etapas no processo de inventário e processo de coleta de dados.

Realizamos, inicialmente, levantamento de teses, dissertações e artigos publicados (Revistas científicas e livros) e elaboramos o fichamento, baseado em leitura aproximativa com o material coletado. Desse modo, identificamos como característica elementar deste trabalho estar relacionado à utilização de documentos escritos como a fonte principal de coleta dos dados.

[...] modalidade de estudo que se propõe a realizar análises históricas e/ou revisão de estudos ou processos tendo como material de análise documentos escritos e/ou produções culturais garimpados a partir de arquivos e acervos. Essa modalidade de estudo compreende tanto os estudos tipicamente históricos ou estudos analíticodescritivos de documentos ou produções culturais, quanto os do tipo "pesquisa do estado-da-arte" (FIORENTINI; LORENZATO, 2006, p. 71). 
Delimitamos o período para levantamento de dados de 2011 a 2019. O Programa OBEDUC- Polo UFMT iniciou suas atividades no ano de 2011, com duração prevista para quatro anos, encerrando as ações organizadas para formação no ano de 2015. Sobretudo, algumas pesquisas de mestrado e doutorado que tomaram a ambiência do programa OBEDUC para seu desenvolvimento foram concluídas e defendidas posteriormente. Desta maneira, estabelecemos o ano de 2019 como limite do período para nosso levantamento de dados para análise, respaldados em ser, nesse ano, que encontramos a produção acadêmica mais recente resultante do projeto no Polo UFMT.

A seleção dos documentos, como teses e dissertações, tomou como principal fonte de acesso o banco de Teses e Dissertações da CAPES. A escolha do banco da CAPES como fonte principal justifica-se por ser a instituição responsável por coordenar e avaliar os diversos programas desenvolvidos em diferentes áreas de conhecimento e por conter registro mais completo da produção acadêmica e científica desses programas. Já o acesso à produção acadêmica: livro e capítulo de livro, aconteceram no banco de dados do projeto OBEDUC, polo UFMT.

Numa segunda etapa, após inventariada toda a produção, passamos ao tratamento e categorização dos dados coletados, dando início à dimensão interpretativa. Esta, repousando na característica de que os dados serão predominantemente descritivos, em que o pesquisador é o principal instrumento para a análise dos dados que se processou indutivamente (BOGDAN \& BIKLEN, 1994).

Realizamos uma leitura aproximativa com os trabalhos selecionados para organizá-los e para definição dos aspectos centrais comuns que pudessem conduzir à elaboração de categorias para posterior análise. O resultado desse trabalho de levantamento de dados, categorização e análise segue apresentado a seguir.

\section{DOS DADOS COLETADOS: TRAÇANDO UM PANORAMA DESCRITIVO DA PRODUÇÃO CIENTÍFICA E PRODUÇÃO ACADÊMICA DESENCADEADAS A PARTIR DAS AÇÕES FORMATIVAS E DE PESQUISA NO PROJETO OBEDUC - POLO UFMT}

Estudos que visam mapear a produção científica e acadêmica a partir de programas desenvolvidos e financiados pela Coordenação de Aperfeiçoamento de Pessoal de Nível Superior (CAPES), em Educação em Ciências e Matemática, como o que aqui está sendo 
proposto, são relevantes tanto para a compreensão das realizações passadas como para a projeção no sentido de promoção de melhorias potenciais para o futuro. De outro modo, comparecem para auxiliar na construção de uma avaliação sobre a efetividade das ações desenvolvidas e sobre os desdobramentos relacionados a esses programas.

No quadro que segue, apresentamos toda a produção científica e acadêmica do Projeto OBEDUC - Polo UFMT, obtida a partir de pesquisa bibliográfica, compreendendo o período de 2011 a 2019.

\begin{tabular}{|c|c|c|c|c|c|}
\hline ANO & Autor(es) & $\begin{array}{c}\text { Tipo da } \\
\text { Publicação }\end{array}$ & Instituição & Orientador & Título da Produção \\
\hline 2012 & $\begin{array}{l}\text { Michelle Cristine } \\
\text { Pinto Tyska } \\
\text { Martinez }\end{array}$ & Dissertação & UFMT & $\begin{array}{l}\text { Dr }^{\mathrm{a}} \text { Gladys } \\
\text { Denise } \\
\text { Wielewski }\end{array}$ & $\begin{array}{l}\text { Um olhar para a abordagem do } \\
\text { conteúdo de Divisão de números } \\
\text { naturais em livros didáticos de } \\
\text { Matemática dos Anos Iniciais do } \\
\text { Ensino Fundamental }\end{array}$ \\
\hline \multirow{5}{*}{2013} & $\begin{array}{l}\text { Aloisio João } \\
\text { Biserra }\end{array}$ & Dissertação & UFMT & $\begin{array}{l}\text { Dra Gladys }^{\mathrm{a}} \\
\text { Denise } \\
\text { Wielewski }\end{array}$ & $\begin{array}{l}\text { Contextualização: Possíveis relações } \\
\text { entre o olhar de professores de } \\
\text { Matemática e os livros didáticos } \\
\text { adotados }\end{array}$ \\
\hline & Rogério Grotti & Dissertação & UFMT & $\begin{array}{c}\text { Profa. Dra. } \\
\text { Marta Maria } \\
\text { Pontin Darsie }\end{array}$ & $\begin{array}{l}\text { O Projeto Observatório da Educação } \\
\text { com Foco em Matemática e Iniciação } \\
\text { à Ciências: possíveis contribuições } \\
\text { na aprendizagem da docência e } \\
\text { perspectiva de configurar-se como } \\
\text { alternativa de atividades } \\
\text { complementares na Formação Inicial } \\
\text { (Licenciatura em Matemática) }\end{array}$ \\
\hline & $\begin{array}{c}\text { Maria do Socorro } \\
\text { Lucinio da Cruz } \\
\text { Silva }\end{array}$ & Dissertação & UFMT & $\begin{array}{c}\text { Profa. Dra. } \\
\text { Marta Maria } \\
\text { Pontin Darsie }\end{array}$ & $\begin{array}{l}\text { Concepções e práticas de professores } \\
\text { do Ensino Fundamental sobre o } \\
\text { ensino de frações: um estudo em } \\
\text { escolas de Cuiabá }\end{array}$ \\
\hline & $\begin{array}{l}\text { Gresiela Ramos } \\
\text { de Carvalho } \\
\text { Souza }\end{array}$ & Dissertação & UFMT & $\begin{array}{l}\text { Dr }^{\mathrm{a}} \text { Gladys } \\
\text { Denise } \\
\text { Wielewski }\end{array}$ & $\begin{array}{l}\text { Números Racionais: concepções e } \\
\text { conhecimento profissional de } \\
\text { professores e as relações com o livro } \\
\text { didático e a prática docente }\end{array}$ \\
\hline & Peterson da Paz & Dissertação & UFMT & $\begin{array}{l}\text { Dr }^{\text {a }} \text { Gladys } \\
\text { Denise } \\
\text { Wielewski }\end{array}$ & $\begin{array}{l}\text { Concepções de professores e o livro } \\
\text { didático: o ensino de divisão nos anos } \\
\text { iniciais do Ensino Fundamental }\end{array}$ \\
\hline \multirow{3}{*}{2014} & $\begin{array}{l}\text { Endrigo Antues } \\
\text { Martins }\end{array}$ & Dissertação & UFMT & $\begin{array}{c}\text { Profa. Dra. } \\
\text { Marta Maria } \\
\text { Pontin Darsie }\end{array}$ & $\begin{array}{l}\text { A Influência da "Matematização" na } \\
\text { aprendizagem de Ciência Naturais: } \\
\text { um estudo sobre a aprendizagem de } \\
\text { cinemática no } 9^{\circ} \text { ano do Ensino } \\
\text { Fundamental }\end{array}$ \\
\hline & $\begin{array}{l}\text { Jeferson Gomes } \\
\text { Moriel Junior }\end{array}$ & TESE & $\begin{array}{l}\text { UFMT/RE } \\
\text { AMEC }\end{array}$ & $\begin{array}{l}\text { Prof }^{a} \text { Dr }^{a} \\
\text { Gladys } \\
\text { Denise } \\
\text { Wielewski }\end{array}$ & $\begin{array}{l}\text { Conhecimento especializado para } \\
\text { ensinar divisão de frações }\end{array}$ \\
\hline & $\begin{array}{l}\text { Daniela Maria de } \\
\text { Almeida }\end{array}$ & TCC & UFMT & $\begin{array}{l}\text { Profa. Dra. } \\
\text { Marta Maria } \\
\text { Pontin Darsie }\end{array}$ & $\begin{array}{l}\text { Diagnóstico, compreensão } \\
\text { interpretação das dificuldades de } \\
\text { aprendizagem em Matemática: o } \\
\text { processo desenvolvido por uma }\end{array}$ \\
\hline
\end{tabular}




\begin{tabular}{|c|c|c|c|c|c|}
\hline & & & & & $\begin{array}{l}\text { acadêmica de Pedagogia, Bolsista do } \\
\text { OBEDUC - UFMT }\end{array}$ \\
\hline & $\begin{array}{l}\text { Jackelynne } \\
\text { Oliveira Silva }\end{array}$ & TCC & UFMT & $\begin{array}{l}\text { Profa. Dra. } \\
\text { Marta Maria } \\
\text { Pontin Darsie }\end{array}$ & $\begin{array}{l}\text { As contribuições do OBEDUC à } \\
\text { formação de uma graduanda em } \\
\text { Pedagogia: o olhar de uma } \\
\text { graduanda/pesquisadora em processo } \\
\text { de formação inicial }\end{array}$ \\
\hline & $\begin{array}{l}\text { Lilian Leandro } \\
\text { da Fonseca }\end{array}$ & Dissertação & UFMT & $\begin{array}{l}\text { Profa. Dra. } \\
\text { Marta Maria } \\
\text { Pontin Darsie }\end{array}$ & $\begin{array}{l}\text { Diagnóstico e encaminhamentos } \\
\text { dados por professores a alunos em } \\
\text { situação de dificuldades de } \\
\text { aprendizagem em Matemática }\end{array}$ \\
\hline 2015 & $\begin{array}{l}\text { Vani Teresinha } \\
\text { Siebert }\end{array}$ & Dissertação & UFMT & $\begin{array}{l}\text { Profa. Dra. } \\
\text { Rute Cristina } \\
\text { Domingos da } \\
\quad \text { Palma }\end{array}$ & $\begin{array}{l}\text { Estudo e ensino de frações: } \\
\text { aprendizagens e dificuldades } \\
\text { docentes no processo de formação } \\
\text { continuada }\end{array}$ \\
\hline \multirow{4}{*}{2016} & Brígida Couto & Dissertação & UFMT & $\begin{array}{l}\text { Profa. Dra. } \\
\text { Marta Maria } \\
\text { Pontin Darsie }\end{array}$ & $\begin{array}{l}\text { O professor articulador e o } \\
\text { atendimento dos alunos em situação } \\
\text { de dificuldade de aprendizagem } \\
\text { matemática em escolas estaduais de } \\
\text { Cuiabá-MT }\end{array}$ \\
\hline & $\begin{array}{l}\text { Margarida Célia } \\
\text { Patrocínio }\end{array}$ & Dissertação & UFMT & $\begin{array}{l}\text { Prof. }^{\mathrm{a}} \text { Dr. }^{\mathrm{a}} \\
\text { Gladys } \\
\text { Denise } \\
\text { Wielewski }\end{array}$ & $\begin{array}{l}\text { A aritmética para as escolas primárias } \\
\text { de Mato Grosso (1910-1946): uma } \\
\text { análise dos documentos oficiais }\end{array}$ \\
\hline & $\begin{array}{l}\text { Kátia Dias } \\
\text { Ferreira Ribeiro }\end{array}$ & TESE & $\begin{array}{l}\text { UFMT/RE } \\
\text { AMEC }\end{array}$ & $\begin{array}{l}\text { Prof. }^{\text {a }} \text { Dr. } \\
\text { Marta Maria } \\
\text { Pontin Darsie }\end{array}$ & $\begin{array}{l}\text { Formação de professores de Ciências } \\
\text { Naturais em uma perspectiva } \\
\text { interdisciplinar e crítica: Reflexões } \\
\text { sobre a contribuição da vivência com } \\
\text { questões sociocientíficas nas na } \\
\text { mobilização e aprendizagem de } \\
\text { conhecimentos para a docência }\end{array}$ \\
\hline & $\begin{array}{l}\text { Marta Andreia } \\
\text { Estancare } \\
\text { Pinheiro Silva }\end{array}$ & Dissertação & UFMT & $\begin{array}{l}\text { Profa. Dra. } \\
\text { Marta Maria } \\
\text { Pontin Darsie }\end{array}$ & $\begin{array}{l}\text { Implicações dos resultados da Prova } \\
\text { Brasil na organização do Sistema } \\
\text { Escolar de Mato Grosso para a } \\
\text { melhoria da qualidade do processo } \\
\text { ensino aprendizagem da Matemática } \\
\text { no Ensino Fundamental }\end{array}$ \\
\hline \multirow[t]{2}{*}{2017} & $\begin{array}{l}\text { Daniele Maria de } \\
\text { Almeida Lima }\end{array}$ & Dissertação & UFMT & $\begin{array}{l}\text { Profa. Dra. } \\
\text { Marta Maria } \\
\text { Pontin Darsie }\end{array}$ & $\begin{array}{l}\text { O atendimento a alunos dos anos } \\
\text { iniciais do Ensino Fundamental em } \\
\text { situação de dificuldades de } \\
\text { aprendizagem em Matemática: } \\
\text { concepções e práticas de Professores } \\
\text { Articuladores de Escolas Estaduais } \\
\text { de Cuiabá-MT }\end{array}$ \\
\hline & $\begin{array}{l}\text { Diana Claudia } \\
\text { Naman }\end{array}$ & Dissertação & UFMT & $\begin{array}{l}\text { Prof }^{\mathrm{a}} \text {. } \\
\text { Dra }{ }^{\mathrm{a}} \text { Gladys } \\
\text { Denise } \\
\text { Wielewski }\end{array}$ & $\begin{array}{l}\text { Apropriações e representações do } \\
\text { processo avaliativo no Ciclo de } \\
\text { Formação Humana por parte de } \\
\text { professores de Matemática de uma } \\
\text { escola estadual de Mato Grosso. }\end{array}$ \\
\hline 2017 & $\begin{array}{l}\text { Marta Maria } \\
\text { Pontin Darsie; } \\
\text { Jacqueline } \\
\text { Borges de Paula }\end{array}$ & LIVRO & $\begin{array}{l}\text { Editora } \\
\text { EdUFMT }\end{array}$ & & $\begin{array}{l}\text { Pesquisa em Educação Matemática e } \\
\text { Ciências: Projeto Observatório da } \\
\text { Educação na Universidade Federal de } \\
\text { Mato Grosso }\end{array}$ \\
\hline
\end{tabular}




\begin{tabular}{|c|c|c|c|c|}
\hline 2019 & $\begin{array}{c}\text { Marta Maria } \\
\text { Pontin Darsie; } \\
\text { Jacqueline } \\
\text { Borges de Paula }\end{array}$ & $\begin{array}{l}\text { Capítulo em } \\
\text { LIVRO }\end{array}$ & $\begin{array}{l}\text { Editora } \\
\text { Espelho } \\
\text { D'Alma }\end{array}$ & $\begin{array}{l}\text { Constituição de Grupos de Estudos e } \\
\text { Pesquisas como espaços de } \\
\text { (re)significação das práticas } \\
\text { educativas e de introdução à pesquisa } \\
\text { sobre processos de ensino- } \\
\text { aprendizagem na Educação Básica - } \\
\text { OBEDUC -Polo UFMT }\end{array}$ \\
\hline
\end{tabular}

Quadro 1 - Síntese de toda a Produção Científica desenvolvida a partir das ações desencadeadas e desenvolvidas no Projeto OBEDUC - Polo UFMT, evidenciada no período de 2011 a 2019.

Fonte: Elaborado pela autora

Nesse período, foram elaboradas 20 produções bibliográficas, resultantes de ações envolvendo momentos formativos, investigativos e de pesquisas. No que tange às pesquisas, todas as problemáticas geradoras delas nasceram a partir das ações que tiveram como cenário e ambiência o Projeto OBEDUC - Polo UFMT. Os autores de toda essa produção bibliográfica eram bolsistas no projeto OBEDUC e/ou colaboradores no Projeto. Os bolsistas atuavam diretamente (dedicando, minimamente, 10 horas semanais ao projeto) nas ações administrativas, operacionais, formativas e de pesquisa, enquanto que os colaboradores participavam das ações formativas e de pesquisa (sem a obrigatoriedade de horas específicas).

Tendo em vista que o Projeto teve duração de quatro anos, pelas características próprias de, no primeiro ano, estar mais voltado à constituição da equipe (chamada para seleção de bolsistas), aproximação com as escolas e suas respectivas comunidades, organização e inventário/diagnóstico dos espaços e sujeitos envolvidos, bem como discussões e estudos para se desenhar o primeiro planejamento e estruturação das ações a serem desenvolvidas, consideramos notório o número de produções científicas e acadêmicas desencadeadas, tendo a média de cinco produções por ano de operação do programa.

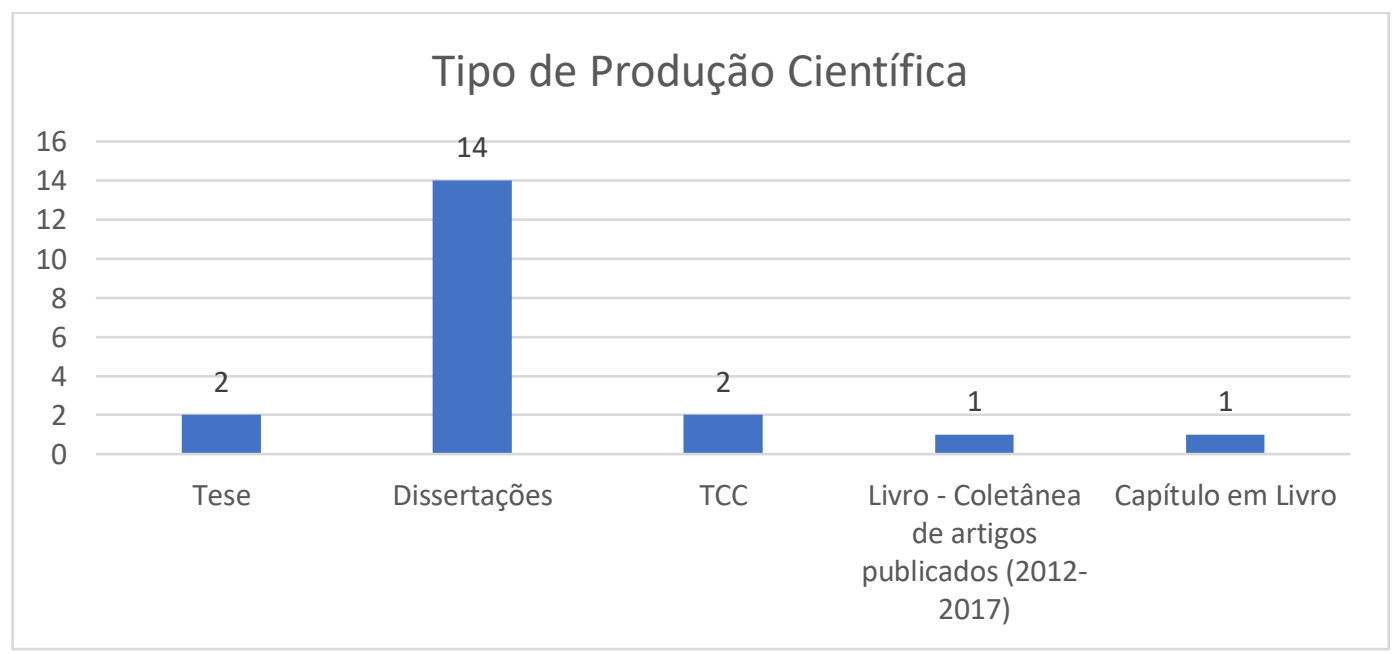

Gráfico 1 - Tipologia da Produção Bibliográfica (Científica e Acadêmica)

Fonte: Elaborado pela autora 
Quando organizamos essas produções por tipologia, podemos destacar a relevância investigativa e de produção de conhecimentos dos estudos realizados, em especial, quando observamos que a ambiência do Projeto OBEDUC - polo UFMT foi cenário para duas pesquisas de doutorado (duração de quatro anos) e 14 pesquisas de mestrado (duração de dois anos). Um total de $78 \%$ da produção bibliográfica advém de pesquisas consistentes realizadas e amparadas pelos programas de Pós-Graduação da UFMT e Programa de Pós-Graduação em Educação em Ciências e Matemática - PPGECEM - Rede Amazônica de Educação em Ciências e Matemática - REAMEC.

Ademais, situamos como produção científica a elaboração de dois Trabalhos de Conclusão de Curso - TCC, produzidos por duas graduandas, bolsistas no Projeto. Esses TCCs apresentam relatos reflexivos das graduandas em formação inicial, agregando uma argumentação crítica sobre o processo de formação vivenciado por ambas no Projeto OBEDUC - Polo UFMT.

Para darmos prosseguimento a nosso exame, elegemos duas categorias à nossa análise e reflexão: Produções Científicas e Produções Acadêmicas. Figuram como produções científicas: as teses, dissertações e TCCs (Trabalhos de Conclusão de Cursos) e como produções acadêmicas: Livro, Capítulo em Livro.

\subsection{Das Produções Científicas: Teses, Dissertações e TCCs}

Quando nos debruçamos para analisar as 18 Produções Científicas, o primeiro destaque observado refere-se a uma concentração de pesquisas cujo foco esteve no campo da Educação Matemática (89\%). Dentre as dezesseis pesquisas desenvolvidas, somente duas (11\%) comparecem como estudos no campo da Educação em Ciências da Natureza e, ainda, em um desses, a investigação foi delineada no estudo do processo de Matematização em Ciências Naturais. 


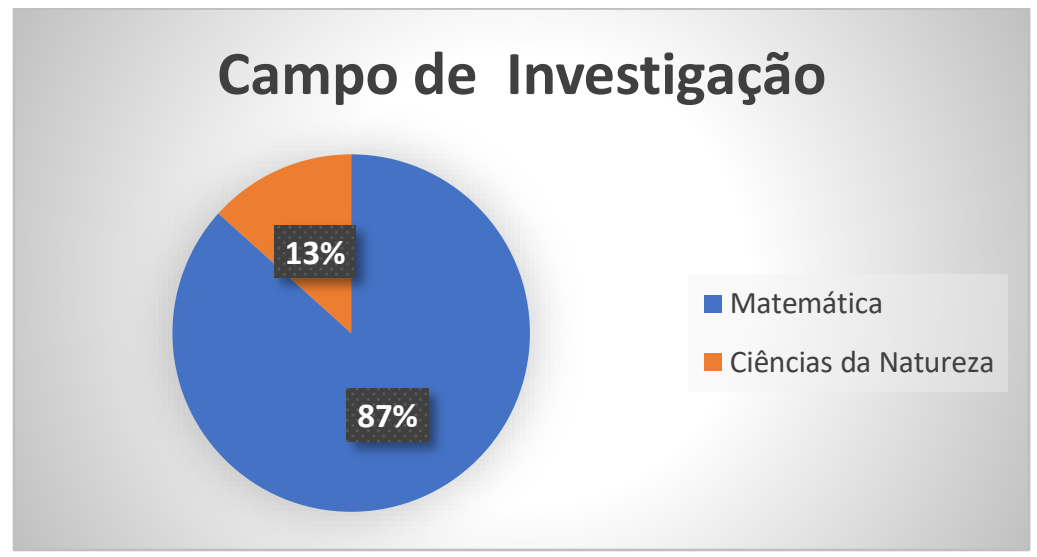

Gráfico 2 - Área da Educação tomada como foco investigativo Fonte: Elaborado pela autora

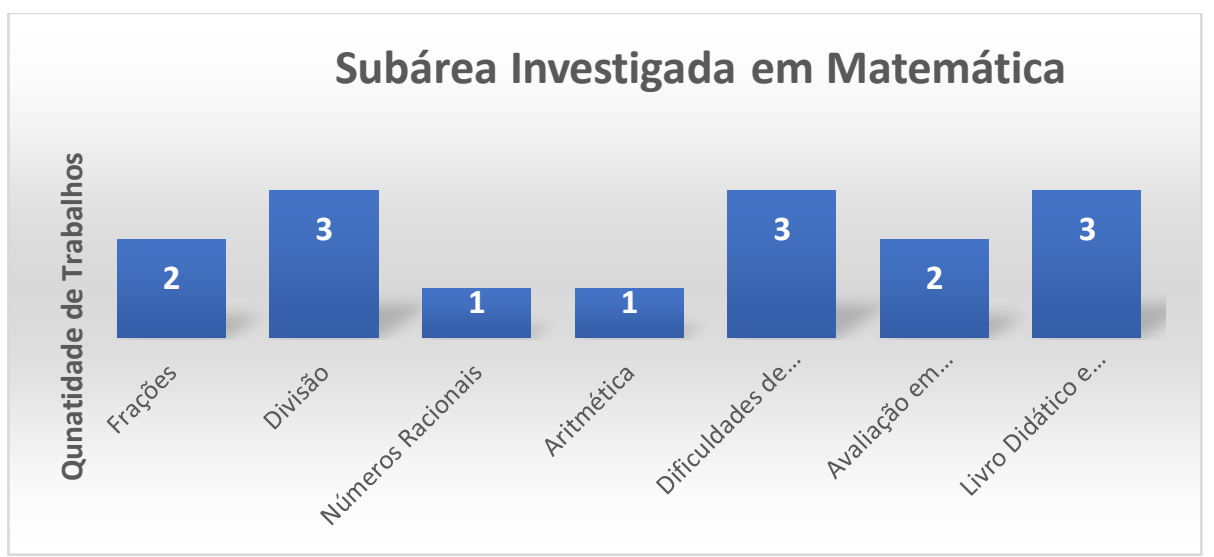

Gráfico 3 - Subárea em Educação Matemática investigada Fonte: Elaborado pela autora

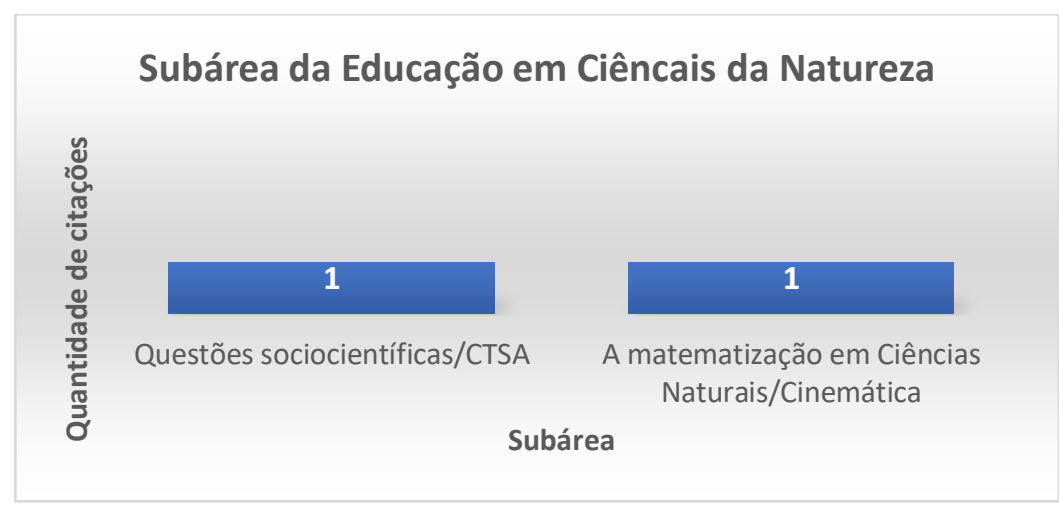

Gráfico 4 - Subárea em Educação em Ciências da Natureza investigada Fonte: Elaborado pela autora 
A ênfase em estudos e pesquisas direcionados à Educação Matemática se justifica porque uma característica do Projeto no Polo UFMT foi que a constituição inicial dos membros da equipe agregou graduandos, professores bolsistas, mestrandos e doutorandos com formação específica em Educação Matemática. Somente a partir do ano de 2013, começaram a compor a equipe membros de outras áreas de conhecimento (Biologia, Física e Química), o que possibilitou ampliarmos estudos relacionados a questões sociocientíficas, CTSA, meio ambiente e sustentabilidade.

Quando observamos o gráfico das palavras-chave nos trabalhos desenvolvidos, identificamos que $97 \%$ delas estão relacionadas a conceitos no processo ensino-aprendizagem em Educação Matemática. Com destaque e maior recorrência para as temáticas: dificuldades de aprendizagem em Matemática e Concepções de Professores.

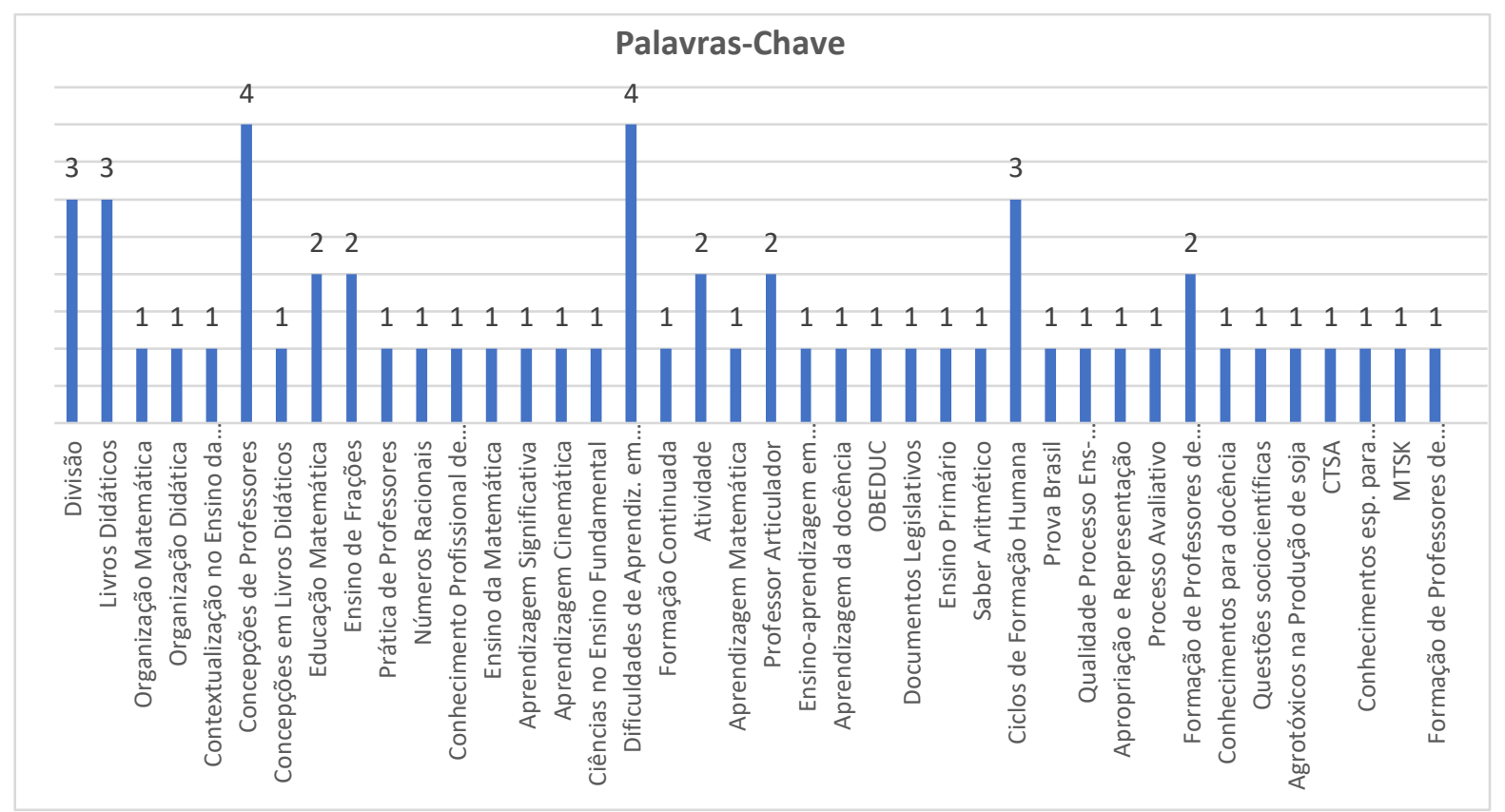

Gráfico 5 - Palavras-Chave encontradas nas Teses e Dissertações Fonte: Elaborado pela autora

Somente 3\% das palavras-chave dizem respeito a estudos envolvendo Educação em Ciências da Natureza, sendo elas: CTSA, Questões sociocientíficas e Formação de Professores em Ciências da Natureza.

No quadro que segue, fica mais evidente o foco em temáticas da Educação Matemática e, quando organizamos as palavras-chave dos trabalhos por ano de publicação, temos mais perceptível que a inserção de outras áreas de conhecimento ocorre mais tardiamente no processo de desenvolvimento do Projeto no Polo UFMT. 


\begin{tabular}{|c|l|}
\hline Ano & \multicolumn{1}{c|}{ Palavras-Chave } \\
\hline 2012 & Divisão; Organização didática; organização Matemática; Livro Didático \\
\hline 2013 & $\begin{array}{l}\text { Concepção e prática de Professores de Matemática; Contextualização; livro didático; Ensino de } \\
\text { frações; Ed. Matemática; Números Racionais; Conhecimento Profissional; Divisão de Racionais; } \\
\text { Observatório da Educação - OBEDUC; Aprendizagem da Docência; Formação Inicial de } \\
\text { Professores de Matemática }\end{array}$ \\
\hline 2014 & $\begin{array}{l}\text { Aprendizagem significativa; Cinemática; Ciências no Ensino Fundamental; Dificuldades de } \\
\text { Aprendizagem Matemática; Ed. Matemática; Conhecimentos especializados para ens. Matemática; } \\
\text { MTSK; Divisão de Frações; Formação de Professores }\end{array}$ \\
\hline 2015 & $\begin{array}{l}\text { Frações; Dificuldades de Aprendizagem Matemática; Formação Continuada; Atividade; Professor } \\
\text { Articulador; ensino-aprendizagem da Matemática; Saber aritmético; Documentos Legislativos; }\end{array}$ \\
\hline 2017 & $\begin{array}{l}\text { Prova Brasil; Qualidade; Processo ensino-aprendizagem em Matemática; Formação de Professores } \\
\text { de Ciências; CTSA; Questões Sociocientíficas; Conhecimentos para docência em Ciências } \\
\text { Apropriação e Representação; Processo Avaliativo; Ciclos de formação Humana; }\end{array}$ \\
\hline
\end{tabular}

OBS: Destacamos em itálico as palavras-chave que evidenciam o campo da Educação em Ciências da Natureza.

Quadro 2 - Palavras-Chave agrupadas por ano de publicação da Produção Científica Fonte: Elaborado pela autora

O Gráfico 6 nos mostra, nas pesquisas desenvolvidas, as fontes utilizadas para coleta de dados. A grande maioria das pesquisas (67\%) foi direcionada a investigar concepções de professores e futuros professores com dificuldades de aprendizagem em Matemática. Os sujeitos nessas pesquisas foram professores da rede pública da Educação Básica e graduandos do curso de Pedagogia na Universidade Federal de Mato Grosso.

É interessante notar que, embora apenas $7 \%$ das pesquisas realizadas tenham tomado como sujeito alunos da Educação Básica, quando observamos o gráfico 6.1, que é um desdobramento do gráfico 6, o montante de alunos que participou dessas pesquisas equivale a (239 alunos) 74\% de sujeitos que se envolveram em ações de coleta de dados.

Também destacamos que, mesmo o Projeto OBEDUC tendo sido a ambiência geradora e integradora dos pesquisadores, encontramos somente em uma das produções científicas o destaque a ele entre as palavras-chave. Tal fato se ancora na amplitude de espaços acadêmicos e institucionais permeados pelas ações no/do projeto e que se constituíram objeto de investigações.

Uma das dimensões - e objetivo do projeto OBEDUC - Polo UFMT- esteve sempre voltada para o estabelecimento de uma proposta que integrasse formação, pesquisa e ação. Desta forma, reconhecemos que o conhecimento acadêmico, o trabalho docente e do pesquisador tratam de instância e espaços dinâmicos, mas que, sobretudo, podem ser tratados e 
trabalhados de modo imbricados e complementares no processo de formação do Educador.

Neste sentido, destacamos a elaboração de dois Trabalhos de Conclusão de Curso (TCC) por graduandas que atuaram no Projeto, com relatos e narrativas potenciais dos estudos e trabalhos por elas desenvolvidos. Neles, as ações formativas no Projeto OBEDUC são efetivamente apropriadas como temática investigativa.

No primeiro TCC, temos o relato de uma graduanda que pesquisou as dificuldades de aprendizagem em Matemática de alunos nos anos iniciais, partindo do ponto de vista dos docentes que trabalham com os alunos. É interessante destacar que esta graduanda (1) foi sujeito na pesquisa realizada pela graduanda (2) como revela em seu TCC.

De forma que, no segundo TCC, a graduanda (2) investigou se as atividades propostas pelo Projeto OBEDUC poderiam contribuir para a aprendizagem da docência. Tomando como sujeito a graduanda (1) que participava do projeto OBEDUC, ela conclui que o espaço e ambiência do projeto possibilitam, aos graduandos, vivenciarem experiências que, possivelmente, só ocorreriam ao concluir o curso ou após certo período no exercício da profissão.

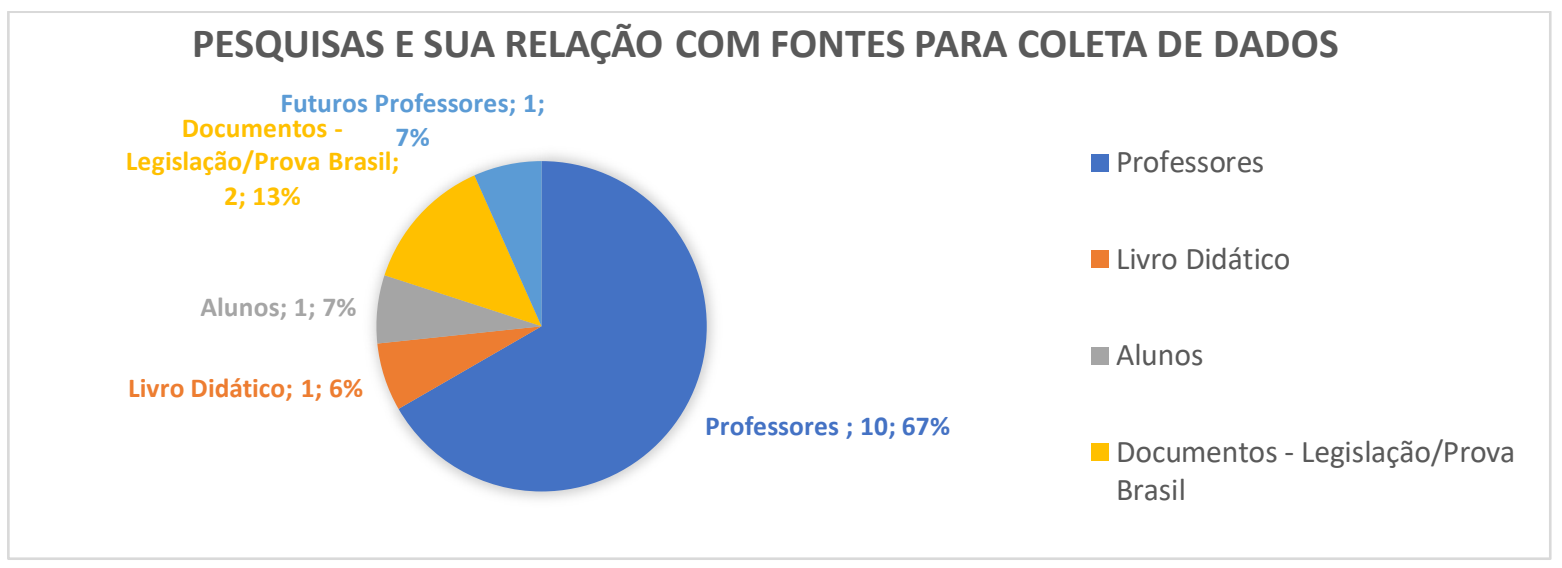

Gráfico 6 - Fonte para coleta de dados utilizada nas pesquisas realizadas Fonte: Elaborado pela autora

O gráfico a seguir apresenta o espectro de segmento dos sujeitos que participaram da coleta de dados nos estudos investigativos realizados. 


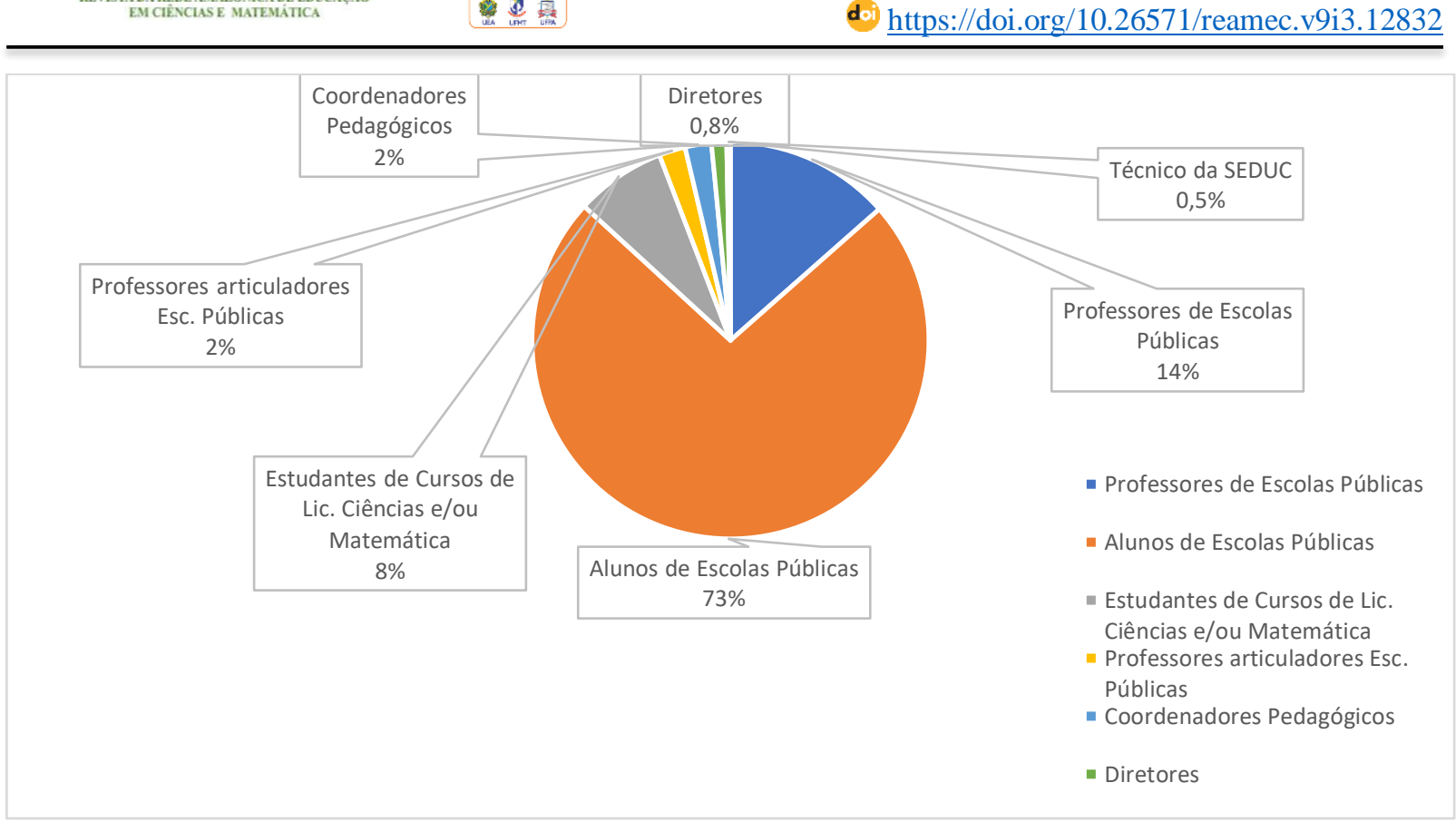

Gráfico 7 - Quantitativo de sujeitos que participaram das investigações de acordo com o segmento administrativo da Rede Pública em que estão inseridos

Fonte: Elaborado pela autora

Interessante observar que sujeitos de todos os níveis foram contemplados nas investigações realizadas, demonstrando a estruturação para compreensão dos imperativos e condicionantes que permeiam todo o processo educativo.

O Gráfico 8 refere-se à metodologia utilizada para a estruturação investigativa e análise dos dados nas pesquisas realizadas. A tendência observada são estudos qualitativos de abordagem interpretativa, principalmente, direcionados a interpretar concepções sobre o processo ensino-aprendizagem, incluindo dificuldades de aprendizagens e avaliação, em contraponto com o livro didático.

Os trabalhos utilizando metodologias "híbridas", compostas por dimensão qualitativa/interpretativa e destaques ou a: pesquisa-ação, histórico comparativo e MTSK, aparecem com frequência menos significativa. Identificamos uma ênfase à metodologia de abordagem qualitativa e cunho interpretativa 


\section{Metodologia - Teses e Dissertações}

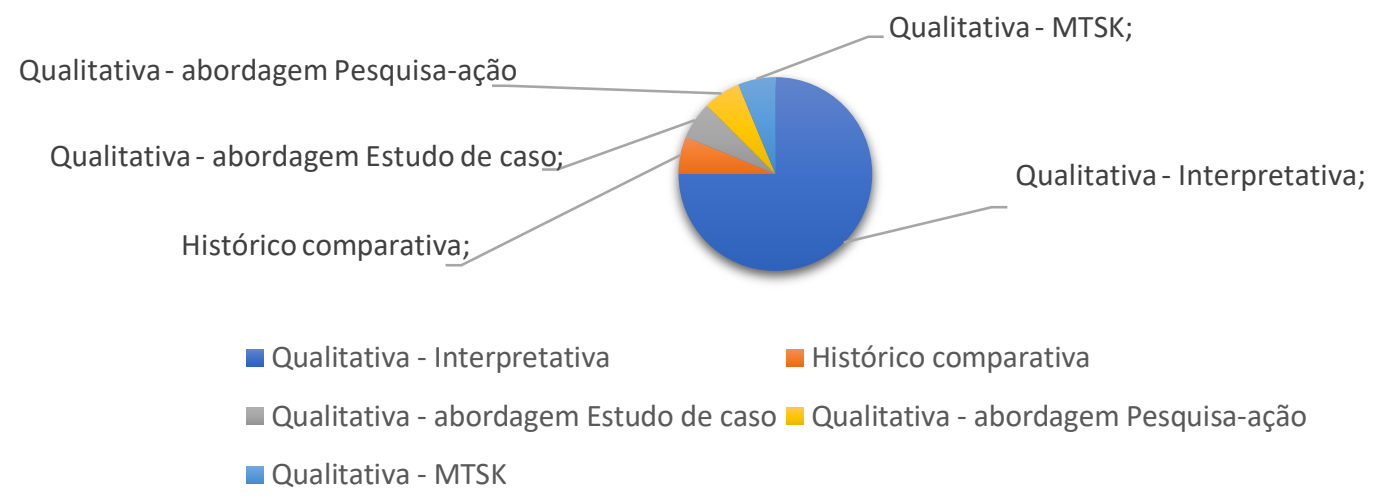

Gráfico 8 - Metodologia empreendida na abordagem, coleta, análise e interpretação dos dados coletados Fonte: Elaborado pela autora

A quantidade de trabalhos desenvolvidos de acordo com os níveis de ensino no processo de escolarização está destacada no Gráfico 9.

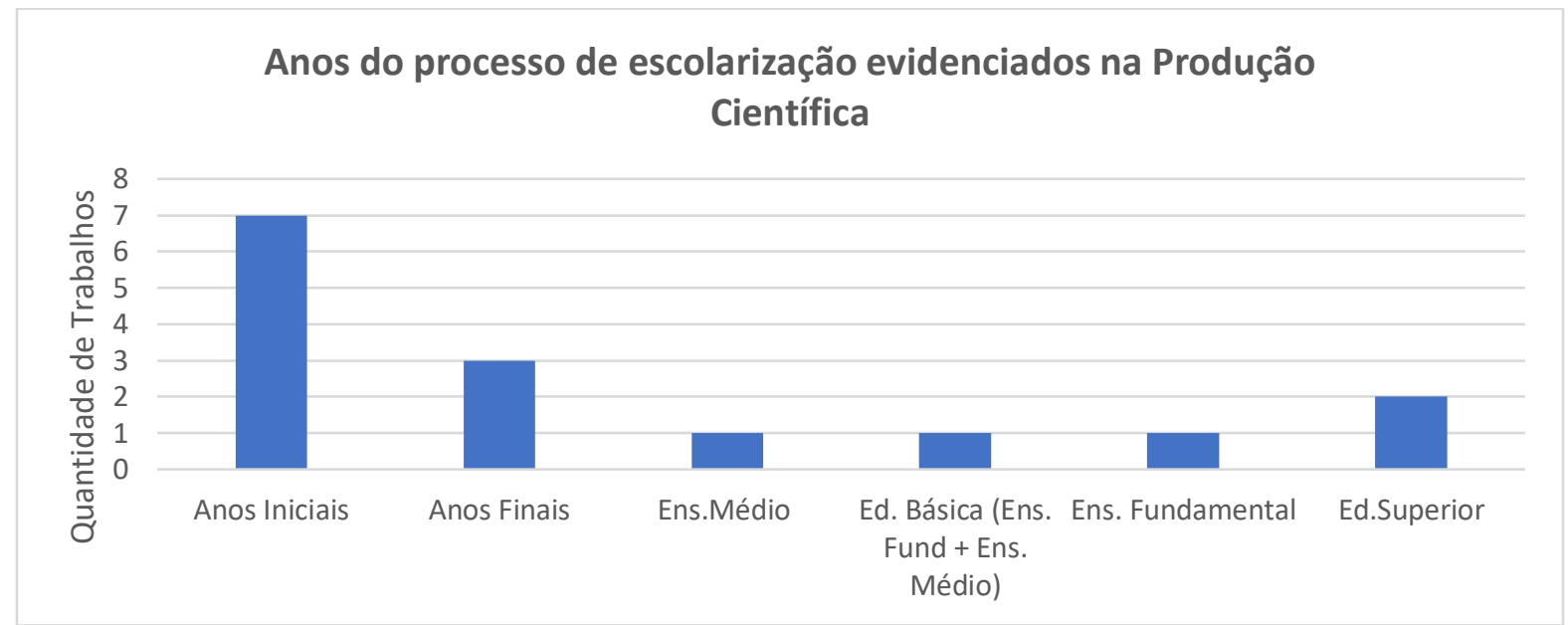

Gráfico 9 - Ano do processo de escolarização evidenciado Fonte: Elaborado pela autora

Detectamos um número relevante de Produções Científicas, tendo como foco o nível dos anos iniciais no processo de escolarização, de aproximadamente 50\%. Quando agregamos as produções que abrangem os anos finais, o destaque ao Ensino Fundamental alcança 73\%. Os demais trabalhos seguem pulverizados entre o Ensino Médio e Educação Superior.

Essa predominância de pesquisas que se voltam ao Ensino Fundamental está diretamente relacionada ao perfil das escolas que se envolveram com o Projeto OBEDUC Polo UFMT. Dentre as seis escolas que participavam, cinco delas contemplam o Ensino Fundamental e apenas uma delas contemplava o Ensino Médio. 
Destacamos que, quanto às pesquisas realizadas na Educação Superior, estas foram desenvolvidas com Licenciandos dos cursos de Matemática e Ciências da Natureza e Pedagogia; no Ensino Superior, sobretudo, o objetivo esteve em investigar as concepções e dificuldades dos futuros professores com o processo ensino-aprendizagem em Matemática.

Entendemos que o projeto OBEDUC, na configuração e desdobramentos de suas ações no Polo UFMT, conseguiu contemplar a grande maioria dos níveis de escolarização, diante de um perfil limitado de escolas (inscritas no projeto) que, a princípio, constituir-se-iam espaços investigativos e de formação.

\subsection{Das Produções Acadêmicas: Livro e Capítulo em Livro.}

Havendo finalizado o Projeto OBEDUC - Polo UFMT no ano de 2015, a equipe elaborou uma coletânea dos artigos publicados e apresentados em eventos regionais, nacionais e internacionais. Esse compilado resultou na concepção e publicação do livro intitulado: "Pesquisa em Educação Matemática e Ciências: Projeto Observatório da Educação na Universidade Federal de Mato Grosso". Esta obra foi organizada pela Prof ${ }^{a}$. Dr. ${ }^{a}$ Marta Maria Pontin Darsie, coordenadora do Projeto no Polo UFMT, e a então doutoranda Prof. a Jacqueline Borges de Paula, responsável pela coordenação das ações pedagógicas e de formação no Projeto.

O livro, publicado em 2017, revela 14 capítulos elaborados por alunos da graduação e pós-graduação que participaram como membros da equipe, atuando tanto na operacionalização das ações do Projeto, como na formação de professores e no desenvolvimento de pesquisas. São destacados, no livro, artigos resultantes de duas teses de Doutoramento, nove pesquisas de Mestrado e três Trabalhos de Conclusão de Curso - TCCs. Todos os artigos selecionados para comporem essa obra foram submetidos, avaliados, aprovados e apresentados em eventos regionais e/ou nacionais.

Em 2019, o polo UNESP do projeto OBEDUC publica o Livro "Educação Científica em questão: a escola como produtora de cultura e sociedade", organizado pelos professores Lizete Maria Orquiza de Carvalho, Washington Luiz Pacheco de Carvalho e Jair Lopes Júnior. Nessa obra, o polo UFMT compareceu com o artigo "Constituição de grupos de estudos e pesquisas como espaços de (re)significação das práticas educativas e de introdução à pesquisa sobre processos de ensino-aprendizagem na educação básica - OBEDUC polo UFMT”. 
O foco neste livro esteve em tratar do processo de constituição e relação entre os Grandes Grupos de Pesquisa e os Pequenos Grupos de Pesquisa (GGPs-PGPs), apresentando seus desdobramentos nos diferentes polos (UNEMAT- UNESP - UFMT) do Projeto OBEDUC. Desse modo, o capítulo elaborado para compor essa obra aborda as ações de estruturação, planejamento, pesquisa e intervenções didáticas, desenvolvidas no polo da Universidade Federal de Mato Grosso (UFMT), câmpus Cuiabá, no decorrer do Projeto do Observatório da Educação, tanto na dimensão do GGP na UFMT, como dos PGPs, nas respectivas unidades escolares.

\section{CONIDERAÇÕES FINAIS}

Observamos que projeto OBEDUC - Polo UFMT buscou o estabelecimento de uma ambiência formativa com foco no desenvolvimento humano das pessoas e de produção de conhecimento, estreitando a relação entre ensino e pesquisa. Assim, trabalhou na perspectiva de um ensino investigativo, reflexivo, crítico e autocrítico, pois havia o entendimento de que a investigação altera, de modo significativo, o conhecimento em processo de construção, em todos os níveis.

De modo intenso e sistemático, o projeto OBEDUC buscou estabelecer uma relação de aproximação e empatia entre Universidade e Escolas, valorizando os saberes diferenciados nos respectivos espaços. O leque das temáticas estudadas e pesquisadas que trataram do Conhecimento Matemático sempre partiu das problemáticas apontadas pelos sujeitos nas respectivas unidades escolares e que coadunavam com a análise dos simulados nestas realizados.

Relevante destacar que, naquelas pesquisas que tomaram como foco investigar quais as percepções dos sujeitos em processo de formação sobre as ações formativas no projeto OBEDUC, estes indicaram que o projeto como um todo estabeleceu ambiência favorável e que contribuiu, de modo ímpar, para as aprendizagens à docência (inicial e continuada), principalmente, ao promover uma complementaridade entre ensino e pesquisa, teoria e prática.

Traçar o panorama, neste momento, da produção científica e acadêmica de um extrato do Programa OBEDUC, neste caso o Projeto OBEDUC- Polo UFMT, no período de 2011 a 2019, para nós, soa como uma prestação de contas à comunidade educativa e à sociedade.

Observamos que o projeto, ao articular Universidade (alunos de graduação e pósgraduação) e escolas (Professores, articuladores, coordenadores e diretores), configurou-se para 
além de um espaço formativo, mas um espaço potencial para investigação, ancorado na perspectiva de fomentar o desenvolvimento de professores e profissionais reflexivo-críticos, num movimento dinâmico de complementaridade entre a teoria e a prática. Dessa forma, a dimensão de constituição de professores pesquisadores sempre permeou todas as ações desenvolvidas no projeto.

Situamos serem de suma importância estudos e trabalhos dessa natureza e, inclusive, que sejam estimulados como linha de investigação, tornando mais eficiente e ampla a divulgação da produção bibliográfica nas áreas envolvidas, bem como para oportunizar que se ampliem reflexões acerca dos aspectos relacionados à formação docente inicial e continuada, ao processo ensino-aprendizagem, à epistemologia e às contribuições das respectivas áreas, tanto a produção de conhecimento acadêmico quanto a melhoria dos processos educacionais.

\section{REFERÊNCIAS}

ALMEIDA, D. M. O atendimento a alunos dos anos iniciais do ensino fundamental em situação de dificuldade de aprendizagem em matemática: concepções e práticas de professores articuladores de escolas estaduais de Cuiabá - MT. Dissertação (Mestrado em Educação), 2017. Instituto de Educação, Universidade Federal de Mato Grosso, Cuiabá, 2017.

BISSERA, A. J. Contextualização: possíveis relações entre o olhar de professores de matemática e os livros didáticos adotados. Dissertação (Mestrado em Educação), 2013. Instituto de Educação, Universidade Federal de Mato Grosso, Cuiabá, 2013.

BOGDAN, R.; BIKLEN, S. Investigação qualitativa em Educação: uma introdução à teoria e aos métodos. Tradução de Maria João Alvarez, Sara Bahia dos Santos e Telmo Mourinho Baptista. Porto: Porto Editora, 1994.

FERNANDES, R.C.A.F.; MEGID NETO, J. Pesquisa sobre o estado da arte em Educação em Ciências: uma revisão em periódicos científicos brasileiros. In: Encontro Nacional de Pesquisa em Educação em Ciências, 6a , 2007. Trabalhos Completos. Disponível em: www.nutes.ufrj.br/abrapec/vienpec/CR2/p124.pdf. Acesso em: 27 dez. 2013.

FIORENTINI, D.; LORENZATO, S. Investigação em Educação Matemática: percursos teóricos e metodológicos. Campinas: Autores Associados, 2006.

FONSECA, L. L. Diagnósticos e encaminhamentos dados por professores a alunos em situação de dificuldades de aprendizagem em matemática. Dissertação (Mestrado em Educação). 2014. Instituto de Educação, Universidade Federal de Mato Grosso, Cuiabá, 2014.

FRACALANZA, H. O que sabemos sobre os livros didáticos para o ensino de ciências no Brasil. 1992. Tese (Doutorado) - Faculdade de Educação, Universidade Estadual de Campinas, 1992. 
FREIRE, Paulo. Política e Educação. 5. ed. São Paulo: Cortez, 2001.

GROTTI, R. O Projeto Observatório da Educação com Foco em Matemática e Iniciação às Ciências: possíveis contribuições na aprendizagem da docência e perspectiva de configurar-se como alternativa de atividades complementares na formação inicial (licenciatura em Matemática). Dissertação (Mestrado em Educação), 2013. Instituto de Educação, Universidade Federal de Mato Grosso, Cuiabá, 2013.

MARTINS, E. A. A influência da "Matematização" na aprendizagem de Ciências Naturais: um estudo sobre a aprendizagem da cinemática no $9^{\circ}$ ano do Ensino Fundamental. Dissertação (Mestrado em Educação). 2014. Instituto de Educação, Universidade Federal de Mato Grosso, Cuiabá, 2014.

MEGID NETO, J. Tendências da pesquisa acadêmica sobre o ensino de Ciências no nível fundamental. Tese (Doutorado) - Faculdade de Educação, Universidade Estadual de Campinas, 1999.

QUIRINO, J. R. A. Um panorama das pesquisas em formação continuada de professores de matemática no programa OBEDUC (2010-2015): uma caracterização da reflexibilidade docente. 2017. Dissertação (Mestrado). Universidade Federal de Mato Grosso do Sul -UFMS, Campo Grandes, Mato Grosso do Sul, 2017.

SILVA, M. S. L. C. Concepções e práticas de professores do ensino fundamental sobre o ensino de frações: um estudo em escolas de Cuiabá. Dissertação (Mestrado em Educação). 2013. Instituto de Educação, Universidade Federal de Mato Grosso, Cuiabá, 2013.

SLONGO, I. P. P.; DELIZOICOV, D. Um panorama da produção acadêmica em ensino de Biologia desenvolvida em programas nacionais de pós-graduação. In: Investigações em Ensino de Ciências, v.11, n.3, 2006. Disponível em: www.if.ufrgs.br/ienci/artigos/Artigo ID156/v11 n3 a2006.pdf. Acesso em: 10 jan. 2014.

TEIXEIRA, P. M.; MEGID NETO, J. Pós-Graduação e pesquisa em ensino de biologia no Brasil: um estudo com base em dissertações e teses. Ciência e Educação. In: Ciência \& Educação (Bauru), v.17, n.3, 2011. Disponível em: http://www.scielo.br/scielo.php?script=sci_arttext\&pid=S151673132011000300004\&lng=en\&nrm=iso. Acesso em: 10 jan. 2021.

TEIXEIRA, P. M. M.; MEGID NETO, J. Investigando a pesquisa educacional: um estudo enfocando dissertações e teses sobre o ensino de Biologia no Brasil. Investigações em Ensino de Ciências, v.11, n.2, ago. 2006.

TEIXEIRA, P. M. M. Pesquisa em Ensino de Biologia no Brasil (1972-2004): um estudo baseado em dissertações e teses. 2008. Tese (Doutorado em Educação) - Faculdade de Educação, Universidade Estadual de Campinas, Campinas, 2008. 


\section{APÊNDICE 1}

\section{AGRADECIMENTOS}

Minha gratidão à Professora $\mathrm{Dr}^{\mathrm{a}}$ Marta Maria Pontin Darsie, por possibilitar estar participando e aprendendo com a Equipe do Projeto OBEDUC - Polo UFMT.

\section{FINANCIAMENTO \\ Não se aplica}

\section{CONTRIBUIÇÕES DE AUTORIA}

Não se aplica.

\section{CONFLITOS DE INTERESSE}

Declaro não haver nenhum conflito de interesse de ordem pessoal, comercial, acadêmico, político e financeiro referente a este manuscrito.

\section{DISPONIBILIDADE DE DADOS DE PESQUISA}

Declaro que o conjunto de dados que dão suporte aos resultados da pesquisa constam do próprio artigo.

\section{CONSENTIMENTO DE USO DE IMAGEM}

Não se aplica.

\section{APROVAÇÃO DE COMITÊ DE ÉTICA EM PESQUISA \\ Não se aplica.}

\section{COMO CITAR - ABNT}

PAULA, Jacqueline Borges de. Panorama da Produção Científica e Acadêmica no Projeto Observatório da Educação com Foco em Matemática e Iniciação em Ciências - UFMT. REAMEC - Rede Amazônica de Educação em Ciências e Matemática. Cuiabá, v. 9, n. 3, e21099, set./dez., 2021. https://doi.org/10.26571/reamec.v9i3.12832.

\section{COMO CITAR - APA}

Paula, J. B. (2021).Panoorama da Produção Científica e Acadêmica no Projeto Observatório da Educação com Foco em Matemática e Iniciação em Ciências - UFMT. REAMEC - Rede Amazônica de Educação em Ciências e Matemática, volume (número), e21099. https://doi.org/10.26571/reamec.v9i3.12832.

\section{LICENÇA DE USO}

Licenciado sob a Licença Creative Commons Attribution-NonCommercial 4.0 International (CC BY-NC 4.0). Esta licença permite compartilhar, copiar, redistribuir o manuscrito em qualquer meio ou formato. Além disso, permite adaptar, remixar, transformar e construir sobre o material, desde que seja atribuído o devido crédito de autoria e publicação inicial neste periódico.

\section{DIREITOS AUTORAIS}

Os direitos autorais são mantidos pelos autores, os quais concedem à Revista REAMEC - Rede Amazônica de Educação em Ciências e Matemática - os direitos exclusivos de primeira publicação. Os autores não serão remunerados pela publicação de trabalhos neste periódico. Os autores têm autorização para assumir contratos adicionais separadamente, para distribuição não exclusiva da versão do trabalho publicada neste periódico (ex.: publicar em repositório institucional, em site pessoal, publicar uma tradução, ou como capítulo de livro), com reconhecimento de autoria e publicação inicial neste periódico. Os editores da Revista têm o direito de proceder a ajustes textuais e de adequação às normas da publicação.

\section{PUBLISHER}

Universidade Federal de Mato Grosso. Programa de Pós-graduação em Educação em Ciências e Matemática (PPGECEM) da Rede Amazônica de Educação em Ciências e Matemática (REAMEC). Publicação no Portal de Periódicos UFMT. As ideias expressadas neste artigo são de responsabilidade de seus autores, não representando, necessariamente, a opinião dos editores ou da referida universidade. 


\section{EDITOR}

Rogerio dos Santos Carneiro (D) 9

\section{HISTÓRICO}

Submetido: 09 de agosto de 2021.

Aprovado: 01 de novembro de 2021.

Publicado: 27 de novembro de 2021. 